\title{
Clinical Description and Outcomes of Australian Children With Invasive Group A Streptococcal Disease
}

\author{
Elise Thielemans, MD, * Jane Oliver, PhD, † Alissa McMinn, RN, $\dagger$ Ciara Baker, MSc, $†$ Philip N. Britton, PhD, $\neq$ \\ Julia Clark, MBBS, § Helen Marshall, MD, $₫$ Christopher C. Blyth, PhD, II Joshua Francis, MBBS, ** \\ Jim Buttery, MD, † Pierre R. Smeesters, PhD, + Nigel Crawford, PhD, † and Andrew C. Steer, PhD $\dagger$
}

\begin{abstract}
Background: Invasive group A streptococcal disease is a severe infection with a high case fatality rate, estimated to cause more than 150,000 deaths per year worldwide. The clinical presentation of this infection is variable, and early diagnosis can be challenging. There are few data on its short- and longer-term outcomes, especially in children. The aim of this study was to assess the clinical presentation, management and short- and longer-term outcomes of invasive group A streptococcal disease in children in Australia. Methods: We undertook a prospective surveillance study of children with laboratory-confirmed invasive group A streptococcus disease admitted to 7 sentinel tertiary and quaternary pediatric hospitals in Australia between July 2016 and June 2018. We collected demographic and clinical data and contacted patients 6 months after discharge to assess longer-term outcomes. Results: We enrolled 181 children, 7 days to 16 years of age. The principal site of invasive infection was blood (126 children, 69.6\%), and the most frequent clinical presentation was pneumonia in 46 children (25.4\%). Twentysix children developed streptococcal toxic shock syndrome (14.4\%), and 74 had severe disease (40.9\%), including 71 admitted to the intensive care unit. Five children died (2.8\%). At discharge and 6 months, $29.3 \%$ and $15.2 \%$ of the children had persisting health problems, respectively.

Conclusions: Invasive group A streptococcal infection in Australian children is frequently severe and has a high long-term morbidity burden, highlighting the need for strengthened clinical care pathways, epidemiological surveillance and prevention strategies.
\end{abstract}

Key Words: Group A Streptococcus, Streptococcus pyogenes, bacteremia, sepsis

(Pediatr Infect Dis J 2020;XX:00-00)

G roup A streptococcus (GAS) is a common human pathogen. ${ }^{1}$ Its most common manifestations are pharyngitis and impe-

Accepted for publication December 20, 2019.

From the *Tropical Diseases Research Group, Murdoch Children's Research Institute, Royal Children's Hospital, Melbourne, Victoria, Australia; $\uparrow$ Paediatric Department, Université Libre de Bruxelles, Bruxelles, Belgium; $\$$ Westmead Children's Hospital and Sydney Medical School, University of Sydney, New South Wales, Australia; §Queensland Children's Hospital, Queensland and School of Clinical Medicine, University of Queensland, Australia; qWomen's and Children's Hospital and Robinson Research Institute, The University of Adelaide, South Australia, Australia; ॥Telethon Kids Institute, University of Western Australia and Perth Children's Hospital, Western Australia, Australia; **Royal Darwin Hospital, Northern Territory, Australia and Menzies School of Health Research, Northern Territory, Australia; $\dagger \dagger$ Monash Health, Monash University, Victoria, Australia; and $\$+$ Hopital Universitaire des Enfants Reine Fabiola, Bruxelles, Belgium.

Supported by Shepherd Foundation of Victoria. The authors have no conflicts of interest to disclose.

Supplemental digital content is available for this article. Direct URL citations appear in the printed text and are provided in the HTML and PDF versions of this article on the journal's website (www.pidj.com).

Address for correspondence: Andrew C. Steer, PhD, Tropical Diseases Research Group, Murdoch Children's Research Institute, Royal Children's Hospital, Flemington Road 50, Parkville, Victoria 3052, Australia. E-mail: andrew. steer@mcri.edu.au.

Copyright $(C 2020$ Wolters Kluwer Health, Inc. All rights reserved.

ISSN: 0891-3668/16/XXXX-0000

DOI: $10.1097 /$ INF.0000000000002596 tigo. GAS can also cause invasive disease. Invasive GAS (iGAS) disease causes more than 150,000 deaths per year worldwide. High-risk groups include children younger than 4 years, the elderly and Indigenous populations..$^{2-5}$

The clinical picture of iGAS disease in children differs from adults. While the overall case fatality rate (CFR) for adults ranges between $10 \%$ and $60 \%$, it is generally lower in children. ${ }^{2,3,6}$ Systemic and local complications are frequent. Bacteraemia without focus is more frequent in children (affecting up to 35\% of patients), while soft tissue infections and streptococcal toxic shock syndrome (STSS) are less common. ${ }^{7}$ STSS is a complication in $2 \%-15 \%$ of children (vs. 3\%-28\% in adults) and can carry a CFR of up to $28 \%{ }^{8-10}$ The principal sites of iGAS infection in children are the skin and the lungs. ${ }^{2,11,12}$ Other iGAS clinical syndromes include osteoarthritis and meningitis, which, although rare, are more common in children than in adults. ${ }^{12-14}$ GAS meningitis presents very rarely $(0.06$ cases per 100,000 children per year) but may be associated with even worse outcomes than meningitis caused by other bacteria. ${ }^{15,16}$

Approximately $20 \%$ of children with iGAS disease present first with a skin lesion. ${ }^{14}$ Varicella is a known risk factor for pediatric iGAS disease, along with use of nonsteroidal anti-inflammatory drugs. ${ }^{17-19}$ Unlike adults, however, almost $50 \%$ of children with iGAS diseases have no known predisposing risk factors. ${ }^{11,14,20}$

iGAS disease is not nationally notifiable in Australia, although it is at the jurisdictional level in Queensland and the Northern Territory and in New South Wales when household transmission is suspected. We sought to describe the clinical presentation, management and outcomes of pediatric iGAS over 2 years in Australia to inform clinical care and prevention strategies.

\section{METHODS}

\section{Study Design}

We performed active surveillance of patients with laboratory-confirmed iGAS disease admitted to 7 major Australian pediatric hospitals between July 1, 2016, and June 30, 2018. Pediatric hospitals included Royal Children's Hospital Melbourne, Victoria; Monash Children's Hospital, Victoria; Perth Children's Hospital, Western Australia; Westmead Children's Hospital, New South Wales; Queensland Children's Hospital, Queensland; Women's and Children's Hospital, South Australia; and Royal Darwin Hospital, Northern Territory. Surveillance was conducted under the auspices of the national paediatric active enhanced disease surveillance (PAEDS) Network (http://www.paeds.edu.au/). ${ }^{21}$

\section{Participants}

All children 18 years of age and younger admitted to a participating hospital with laboratory-confirmed iGAS disease were eligible for inclusion. We defined laboratory-confirmed iGAS disease as the isolation by routine bacterial culture and/or nucleic acid detection of GAS from a normally sterile bodily site (eg, blood, pleural fluid, joint fluid, cerebrospinal fluid). Some cases were diagnosed in another hospital and transferred to a PAEDS hospital for management. 


\section{Procedures}

Diagnostic laboratory staff informed the local study team when GAS was isolated from a normally sterile site sample of a patient. The patient and family were invited to participate. Following written informed consent, demographic and clinical data were collected and entered onto a RedCap database. ${ }^{22}$ Six months after discharge, all participants received an email with a linked survey on their health. Data were clarified by a telephone call if required. Some cases were identified by International Statistical Classification of Diseases and Related Health Problems, Tenth Revision, Australian Modification audits and were retrospectively recruited and data collected with an approved waiver of consent.

\section{Clinical Data and Definitions}

We collected data on previous medical consultations during the 7 days preceding the iGAS hospitalization. Data included patients' clinical presentation and course, management and outcome. Severe iGAS was defined as requiring admission to intensive care, mechanical ventilation or inotropes. The clinician in charge of the patient diagnosed the clinical syndrome.

Outcomes of interest were death, disability or deficit. A disability was, as defined by the World Health Organization, any impairment, activity limitations or participation restrictions in a permanent state. ${ }^{23}$ We used the word deficit for any impairment, activity limitations or participation restrictions but with the possibility to improve. We collected information on deficits and disability at 6 months by contacting the parents/guardians of the child via email initially and, if they did not respond to email, we contacted them by telephone.

\section{Analysis}

Demographic and clinical data were analyzed descriptively and reported as proportions of total patients. When reporting laboratory findings and the duration of certain features (eg, length of hospital stay), the median and interquartile range (IQR) were stated. We measured the association between severe disease and clinically relevant selected factors using risk ratio (RR) estimates with $95 \%$ confidence intervals (CIs). STATA 14 (Stata Corporation, College Station, TX) was used for all analyses.

\section{Ethics}

Ethics approval was obtained from the RCH Human Research Ethics Committee, HREC\#36339, and extended to all jurisdictions. A waiver of consent for retrospectively collected data was obtained, as was approval for conducting the 6-month followup email survey.

\section{RESULTS}

We identified 181 children with laboratory-confirmed iGAS disease during the 2-year period. A descriptive epidemiological analysis of these patients is published elsewhere. ${ }^{24}$ There was a male predominance $(n=107 ; 59.1 \%)$ and a median age of 2.9 years (range: 7 days to 16 years and 9 months) at hospital admission. Twenty-one (11.6\%) children were of Aboriginal or Torres Strait Island ethnicity.

\section{Site of Infection and Clinical Syndrome}

GAS was isolated in the blood of 126 patients, of whom 13 had a second positive invasive site (Table 1 ). In addition to having a sterile site isolate, $43(23.8 \%)$ had GAS isolated from a noninvasive site, most frequently a skin swab (23 patients).

Pneumonia occurred in 46 children $(25.4 \%)$, of whom 12 had empyema. Osteoarticular infection was the next most common syndrome $(23.8 \%)$, followed by skin and soft tissue infections
(20.4\%) and bacteraemia without focus (19.9\%). Six children had meningitis. Twenty-two were diagnosed with 2 different clinical syndromes and 1 with 3 clinical syndromes (soft tissue infection, arthritis and osteomyelitis).

\section{Streptococcal Toxic Shock Syndrome}

Twenty-six children (14.4\%) met the criteria for STSS; all 26 had severe disease and 4 died (the STSS CFR was 15.4\%). All STSS cases except one had symptoms lasting at least 2 days. Ten STSS patients had pneumonia, and 7 had bacteraemia without focus. All 5 children diagnosed with necrotizing fasciitis had STSS.

\section{Preceding Medical Consultations}

In the 7 days preceding hospitalization for iGAS disease, 142 patients $(78.5 \%)$ had consulted a doctor. Of these, 116 visited a general practitioner $(64.1 \%), 60$ visited an emergency department (33.1\%) and 34 visited both (18.8\%). Seventy patients (38.7\%) had consulted a doctor more than once. The most common diagnosis at these visits was an unspecified viral illness. Among patients visiting a general practitioner, $65(56 \%)$ were referred to an emergency department, of whom 50 actually attended, and of these, 41 were hospitalized and 9 were sent home. In total, 86 children $(47.5 \%)$ were seen by clinicians but were sent home in the week preceding hospitalization for iGAS disease.

On arrival at the emergency department (on the day of admission), 152 children (84\%) had symptoms lasting at least 2 days, and $113(62.4 \%)$ at least 3 days. The most common presenting clinical feature was fever (160 patients, $88.4 \%$, Table 2 ), with a median duration of 3 days (range: $<24$ hours to 14 days).

Sixty-three children $(34.8 \%)$ had a preexisting medical condition; 25 had a respiratory diagnosis (including asthma) and 23 had eczema. In the week preceding admission, 79 (43.6\%) reported having received at least 1 dose of nonsteroidal anti-inflammatory drugs. Among those, 77 (97.5\%) presented with fever. In the preceding month, 13 children $(7.2 \%)$ had pyoderma and 1 had a varicella zoster virus infection.

\section{Laboratory Results}

Laboratory results are detailed in Supplemental Digital Content 1, http://links.lww.com/INF/D765. A full blood count was obtained from 180 children, and the median hemoglobin, platelet count, white cell count and neutrophil count were $118 \mathrm{~g} / \mathrm{L}$, $278 \times 10^{9} / \mathrm{L}, 14.4 \times 10^{9} / \mathrm{L}$ and $9.9 \times 10^{9} / \mathrm{L}$, respectively. The C-reactive protein concentration was assayed in 171 patients $(94.5 \%)$, with a median value of $162 \mathrm{mg} / \mathrm{L}$. The C-reactive protein concentration was over $100 \mathrm{mg} / \mathrm{L}$ in $64.9 \%$ of patients and over $200 \mathrm{mg} / \mathrm{L}$ in $36.8 \%$ of patients.

\section{Severity}

Seventy-four children $(40.9 \%)$ met our criteria for severe disease (Table 3). Seventy-one of these were admitted to the intensive care unit (ICU), including 50 within the first 24 hours of admission to the hospital. A further 25 children (13.8\%) had liver, renal or coagulation abnormalities, or acute respiratory distress syndrome (without requiring intubation).

There was no association between age, sex or Aboriginal and Torres Straight Islander status with disease severity (Supplemental Digital Content 2, http://links.lww.com/INF/D766). All 5 patients with necrotizing fasciitis had severe disease, as did all 6 with meningitis. Of the 46 children with pneumonia, 35 (76.1\%) had severe disease $(\mathrm{RR}=2.6,95 \% \mathrm{CI}$ : 1.9-3.6, Table 3$)$.

Of the 83 patients with rash, $40(48.2 \%)$ had severe disease $(\mathrm{RR}=1.3,95 \% \mathrm{CI}: 0.98-2$, Table 2$)$, and 14 of 22 children with a petechial or purpuric rash $(63.6 \%)$ had severe disease $(\mathrm{RR}=$ 
TABLE 1. Clinical Syndromes and Microbiologic Sites of Infection in Children With Invasive Group A Streptococcal Disease as Notified to the PAEDS Network, Australia (July 2016 to June 2018)

\begin{tabular}{|c|c|c|c|c|c|c|c|c|}
\hline \multirow[b]{2}{*}{ Clinical Syndrome* } & \multirow[b]{2}{*}{ Total } & \multicolumn{6}{|c|}{ Microbiological Site of Infection } & \multirow[b]{2}{*}{$\begin{array}{c}\text { Case Fatality } \\
\text { Rate }(\%)\end{array}$} \\
\hline & & Blood & $\begin{array}{l}\text { Pleural Fluid/ } \\
\text { Pulmonary Tissue }\end{array}$ & $\begin{array}{c}\text { Osteoarticular } \\
\text { Sample }\end{array}$ & $\begin{array}{c}\text { Deep Soft } \\
\text { Tissue }\end{array}$ & $\mathrm{CSF}$ & Other $\dagger$ & \\
\hline Pneumonia & 46 & 17 & 32 & - & - & - & 1 & 6.5 \\
\hline Empyema & 12 & 1 & 10 & - & - & - & 1 & 0 \\
\hline Bacteraemia without focus & 36 & 36 & - & - & - & - & - & 5.6 \\
\hline Skin and soft tissue infection & 37 & 32 & - & - & 5 & 1 & 2 & 0 \\
\hline STSS & 26 & 19 & 5 & - & 1 & 2 & - & 15.4 \\
\hline Osteomyelitis & 26 & 19 & - & 8 & 2 & - & - & 0 \\
\hline Arthritis & 21 & 15 & - & 11 & - & - & - & 0 \\
\hline Meningitis & 6 & 3 & - & - & - & 4 & - & 0 \\
\hline Other clinical syndrome $\ddagger$ & 21 & 14 & - & 2 & 2 & - & 3 & 0 \\
\hline All patients & 181 & 126 & 32 & 18 & 8 & 4 & 6 & 2.8 \\
\hline
\end{tabular}

*Patients could have more than 1 clinical syndrome.

†Other microbiological sites were mastoid cavity $(\mathrm{n}=1)$, brain abscess $(\mathrm{n}=1)$, chest fluid $(\mathrm{n}=1)$, toe tissue $(\mathrm{n}=1)$ and retropharyngeal abscess $(\mathrm{n}=1)$.

$\doteqdot$ Other clinical syndromes were peritonitis $(n=4)$, surgical site infection $(n=4)$, retropharyngeal abscess $(n=3)$, mastoiditis $(n=3)$, encephalitis $(n=1)$, cerebral abscess $(n=1)$, postauricular abscess $(n=1)$, ear infection $(n=1)$, epiglottis $(n=1)$, peritonsillar abscess $(n=1)$ and subperiosteal orbital abscess $(n=1)$.

PAEDS indicates Paediatric Active Enhanced Disease Surveillance.

TABLE 2. Presentation Versus in Children With Invasive Group A Streptococcal Disease as Notified to the PAEDS Network, Australia (July 2016 to June 2018)

\begin{tabular}{|c|c|c|c|}
\hline \multirow[b]{2}{*}{ Presentation } & \multirow{2}{*}{$\frac{\text { Total }}{\mathrm{N}(\%)}$} & \multicolumn{2}{|c|}{ Severe Cases } \\
\hline & & $2(\%)$ & $\mathrm{RR}^{*}(95 \% \mathrm{CI})$ \\
\hline \multicolumn{4}{|l|}{ Prior ED/GP consultations $\dagger$} \\
\hline 0 in the last 7 days & $95(52.5)$ & $32(34)$ & $0.7(0.5-0.98)$ \\
\hline 1 or more in the last 7 days & $86(47.5)$ & $42(49)$ & $1.4(1.02-2.1)$ \\
\hline \multicolumn{4}{|l|}{ Symptoms } \\
\hline Vomiting & $90(49.7)$ & $38(42)$ & $1.1(0.8-1.5)$ \\
\hline Limb pain & $74(40.9)$ & $22(30)$ & $0.6(0.4-0.9)$ \\
\hline Fever & $152(84.9)$ & $64(42)$ & $1.2(0.7-2.1)$ \\
\hline Diarrhea & $47(26)$ & $25(53)$ & $1.5(1.03-2.1)$ \\
\hline Symptoms lasting $\geq 2$ days & $152(84)$ & $64(42)$ & $1.2(0.7-2.1)$ \\
\hline Symptoms lasting $\geq 3$ days & $113(62.4)$ & $46(41)$ & $0.99(0.7-1.4)$ \\
\hline \multicolumn{4}{|l|}{ Clinical examination } \\
\hline Rash (all) & $83(45.9)$ & $40(48)$ & $1.4(0.98-2)$ \\
\hline Petechial/ purpuric rash & $22(12.2)$ & $14(64)$ & $1.7(1.2-2.5)$ \\
\hline Hypotension & $44(24.3)$ & $35(80)$ & $2.8(2.1-3.8)$ \\
\hline \multicolumn{4}{|l|}{ ED Triage } \\
\hline Category 1 & $12(6.6)$ & $10(83)$ & $2.2(1.6-3)$ \\
\hline All patients & $181(100)$ & $74(40.9)$ & \\
\hline
\end{tabular}

*Test of association between the severe and nonsevere cases.

$\dagger$ Seen by a doctor in the last 7 days preceding the hospitalization and sent home.

ED indicates emergency department; GP, general practitioner; NF, necrotizing fasciitis; PAEDS, paediatric active enhanced disease surveillance; $R R$, relative risk.

1.7, 95\% CI: 1.2-2.5, Table 2). Thirty-five of the 44 children with a low blood $\mathrm{pH}$ had severe disease $(79.5 \%, \mathrm{RR}=1.6, \mathrm{CI}: 1.2-2.2)$, and 4 of the 5 with a low neutrophil count had severe disease $(80 \%$, $\mathrm{RR}=2.1, \mathrm{CI}: 1.3-3.3$, Supplemental Digital Content 1, http://links.lww. com/INF/D765). Children who had previously consulted a doctor and were subsequently sent home in the 7 days before hospitalization were at higher risk of severe disease $(\mathrm{RR}=1.4,95 \% \mathrm{CI}$ : 1.02-2.1) compared with children who were hospitalized at their first medical presentation. We found no association between the use of nonsteroidal anti-inflammatory drugs and the severity of the disease $(\mathrm{RR}=1.3, \mathrm{CI}$ : $0.9-1.8)$.

\section{Treatment}

The median length of stay in hospital was 10 days (IQR $=5-15$ days, range: $<1$ day to 65 days). Of the 71 children admitted to ICU, 41 required intubation and 5 received extracorporeal membrane oxygenation. The median length of stay in ICU was 4 days (IQR = 2-8 days, range: $<1$ day to 31 days).

Antibiotic treatment was initiated in the emergency department for 133 children (73.5\%). The median duration of total antibiotic treatment was 20 days (IQR $=12-35$ days, range: $<1$ day to 79 days). The median duration of intravenous antibiotic treatment was 9 days (IQR $=5-14$ days, range: $<1$ day to 49 days). A lincosamide antitoxin antibiotic (clindamycin or lincomycin) was administered to 102 children $(56.4 \%$ ) and intravenous immunoglobulin (IVIG) was administered to 16 children (8.8\%). Seventy-six (42\%) did not receive either treatment. Among the 74 patients with severe disease, $59(79.7 \%, \mathrm{RR}=3.0, \mathrm{CI}: 1.9-4.9)$ and $15(20.3 \%, \mathrm{RR}=2.6, \mathrm{CI}$ : 2.1-3.3) received a lincosamide antibiotic and IVIG, respectively. Of the 26 patients with STSS, 23 (88.5\%) received a lincosamide antibiotic and $10(38.5 \%)$ received IVIG.

A surgical procedure was performed in 109 patients $(60.2 \%)$; 42 patients had surgery in the first 24 hours of hospitalization, 34 patients required 2 or more procedures (maximum 9 procedures) and 3 patients underwent multiple limb amputation.

\section{Outcomes}

Five patients died (CFR 2.8\%). Three of those had pneumonia and 2 had bacteraemia without focus. Including deaths, 58 patients $(32 \%)$ had an adverse outcome and 53 children $(29.3 \%)$ had at least 1 deficit or disability at discharge. Deficits included impairment of mood, intellect or behavior (49 patients, 27.1\%), fatigue (35 patients, $19.3 \%$ ) and physical impairment (10 patients, 5.5\%). Five patients had severe mobility disabilities: 3 from multiple amputations; 1 patient had residual hemiplegia; and 1 had severe dystonia.

Ninety-nine patients $(54.7 \%)$ completed the 6-month follow-up survey. The demographic characteristics, severity and outcome at discharge of these patients were similar to the sample as a whole, except that only 5 children $(5.1 \%)$ had Aboriginal or Torres Strait Island ethnicity compared with $21(11.6 \%)$ of the full sample $(\mathrm{RR}=0.4, \mathrm{CI}: 0.2-0.9$, Supplemental Digital Content 3, http:// links.lww.com/INF/D767). Among these 99 patients, 55 attended at least 1 outpatient appointment related to their prior admission for iGAS disease. Seven patients required at least 1 hospital readmission. Fifteen patients $(15.2 \%)$ continued to experience health issues 6 months after discharge (Supplemental Digital Content 4, http:// links.lww.com/INF/D768). One child (who had GAS meningitis) experienced hearing and vision loss. 
TABLE 3. Clinical Syndromes and Infection Severity in Children With Invasive Group A Streptococcal Disease as Notified to the PAEDS Network, Australia (July 2016 to June 2018)

\begin{tabular}{lcccr}
\hline \hline & \multicolumn{2}{c}{ Total } & & \multicolumn{2}{c}{ Severe Cases } \\
\cline { 2 - 3 } Clinical Syndrome & $\mathrm{N}(\%)$ & $\mathrm{n}(\%)$ & $\mathrm{RR}(95 \% \mathrm{CI})$ \\
\hline Pneumonia & $46(25.4)$ & $35(76)$ & $2.6(1.9-3.6)$ \\
Empyema & $12(6.6)$ & $9(75)$ & $2(1.3-2.8)$ \\
Bacteraemia without focus & $36(19.9)$ & $10(28)$ & $0.6(0.4-1.1)$ \\
Skin and soft tissue infection $\dagger$ & $32(17.7)$ & $5(16)$ & $0.3(0.1-0.8)$ \\
STSS & $26(14.4)$ & $26(100)$ & $3.2(2.6-4.1)$ \\
Osteomyelitis & $26(14.4)$ & $4(15)$ & $0.3(0.1-0.9)$ \\
Arthritis & $21(11.6)$ & $2(10)$ & $0.2(0.1-0.8)$ \\
Meningitis & $6(3.3)$ & $6(100)$ & $2.6(2.1-3.1)$ \\
Necrotizing fasciitis & $5(2.8)$ & $5(100)$ & $2.6(2.1-3.1)$ \\
Other clinical syndrome & $21(11.6)$ & $9(43)$ & $1.05(0.6-1.8)$ \\
All patients & $181(100)$ & $74(40.9)$ & \\
\hline
\end{tabular}

*Test of association between the severe and nonsevere cases.

$\dagger$ Excluding NF.

$\mathrm{NF}$ indicates necrotizing fasciitis; PAEDS, paediatric active enhanced disease surveillance; RR, relative risk.

Adverse outcomes at discharge were most frequent for patients with GAS arthritis (52.4\%) and necrotizing fasciitis (80\%, Supplemental Digital Content 5, http://links.lww.com/INF/D769 and 6; http://links.lww.com/INF/D770). Of the 26 patients who had STSS, 19 had an adverse outcome at discharge $(73.1 \%$; RR $=2.9$, CI: $2-4.2)$ including 4 deaths. We were able to collect follow-up data for 14 patients with STSS; $7(50 \%)$ had an adverse outcome at 6 months $(\mathrm{RR}=5.3, \mathrm{CI}: 2.3-12.3)$.

\section{DISCUSSION}

In this study, we reveal a high frequency of severe disease among children with iGAS disease, resulting in complex and prolonged treatment, followed by longer-term sequelae for many patients. Nearly half of the patients were seen and discharged by a doctor in the week preceding their hospitalization and diagnosis.

Our study is the first to assess the outcome of iGAS disease in children at discharge and at 6 months. At discharge, $32 \%$ of our cohort had ongoing health issues as a result of their infection. This proportion is similar to rates of sequelae following invasive meningococcal disease described in Australian children (37.6\%), but far higher than that reported in previous retrospective studies of children with iGAS disease (less than 3\% with sequelae). ${ }^{20,25,26}$ At 6-month follow-up, $15.2 \%$ of the children in our study had persisting health issues, comparable to the $11 \%-19 \%$ rate of long-term sequelae described for invasive meningococcal disease. ${ }^{27}$ The CFR of $2.8 \%$ in our study is lower than that described for adults with iGAS disease, but consistent with preexisting literature for children. . $^{2,3,6}$

We report a high proportion of severe disease, with $39.2 \%$ of patients admitted to the ICU and $60.2 \%$ requiring a surgical procedure. This reflects the serious nature of iGAS disease, and also that our surveillance was conducted at specialist tertiary hospitals where the most unwell patients are managed.

In Australia, a lincosamide antibiotic (usually clindamycin) and IVIG are generally recommended for the management of severe iGAS disease, albeit with limited evidence in children. ${ }^{28-30}$ Previous studies suggest that adding clindamycin may reduce mortality. ${ }^{31}$ An adult study demonstrated increased survival when IVIG was used for patients with STSS (34\% vs. $87 \%$ survival rate at 30 days). ${ }^{32,33}$ In our study, a lincosamide antibiotic was prescribed for nearly $80 \%$ of patients with severe disease, but IVIG in only $20.3 \%$ of these (38.5\% of STSS). This apparent low use of IVIG has been reported in other studies of the management of children with severe iGAS and reinforces the need for widely available standardized management guidelines. ${ }^{8,9}$

Forty-eight percent of febrile patients received a nonsteroidal anti-inflammatory drug in the preceding week. This proportion is lower than that reported in the study by Walsh et a ${ }^{34}$ of febrile Australian children (77\%). We did not identify nonsteroidal antiinflammatory drugs as a risk factor for iGAS disease.

A high proportion of patients in our cohort had pneumonia $(25 \%)$, and approximately $75 \%$ of these patients had severe disease. ${ }^{35,36}$ The high caseload and severity may be related to the 2017 winter influenza outbreak in Victoria. ${ }^{37}$ Epidemiologic links between influenza and iGAS infection have been described previously. Mouse models have showed that influenza enhances the virulence of GAS in the alveoli. ${ }^{38-40}$

Our study supports emerging data that describe a phenomenon of a nonspecific febrile prodrome lasting some days among pediatric patients with iGAS disease. ${ }^{41}$ Almost half of our patients $(47.5 \%)$ had consulted a doctor in the week before hospitalization, including $33.2 \%$ at an emergency department, but were sent home. In a previous study of 521 children with meningitis or sepsis in Ontario, Canada, 21.9\% had repeated emergency department visits before admission to hospital. ${ }^{42}$ In our study, children sent home at their first consultation had a higher risk of subsequently developing severe disease compared with those admitted directly to hospital ( $R R=1.5,95 \%$ CI: $1.02-2.1)$ While the presenting symptoms and signs during this febrile prodrome period appear nonspecific, this does raise opportunities to investigate clinical criteria and biomarkers which may help identify patients earlier, perhaps enabling them to receive antibiotic treatment and potentially prevent invasive manifestations from occurring. Additionally, close contacts of patients with iGAS disease have an approximately 2000 times increased risk of secondary disease $(\mathrm{RR}=1.9$; 95\% CI: 1.2-2.9). Should iGAS patients become notified rapidly, it is theoretically possible to prevent secondary disease by providing close contacts with prophylactic antibiotics. ${ }^{43}$

There are limitations to our study. First, our case definition required isolation of GAS from a sterile site. This likely led to missed cases where GAS is isolated from nonsterile sites, but the disease might still be considered invasive (as may occur in patients with retropharyngeal abscess, mastoiditis or necrotizing fasciitis). Second, we recruited only in tertiary and quaternary centers, which could have resulted in underrecognition of the true burden of pediatric iGAS disease, and also likely skewed the clinical picture of the cases toward higher severity. Third, there was a $45 \%$ loss to follow-up for the 6-month assessment. While the profile of the sample at 6 months was largely similar to that of the overall cohort, we cannot be sure that the sample was representative.

Our study provides further impetus for establishing a national surveillance system for iGAS disease in children and adults in Australia. In addition to optimizing clinical management of iGAS disease, there is a need to closely monitor the epidemiology of this condition. Enhanced surveillance of iGAS may contribute to improving early recognition of this serious disease and improve the effectiveness of prevention activities.

\section{ACKNOWLEDGMENT}

We thank all the children and families included in this study, as well as the research nurses and the laboratory staff at the participating hospitals: A/Prof Andrew Daley and Ms Gena Gonis from the Royal Children's Hospital, Melbourne; Mr Andrew Lawrence from Women's and Children's Hospital, South Australia; Dr Avram Levy and Ms Jacinta Bowman from Perth Children's Hospital; Ms Despina Kotsanas from Monash Health; the Territory Pathology 
microbiology staff; Elizabeth Clark, Kathryn Monaghan and Narelle George from Pathology Queensland; and the staff members of the Children's Microbiology Department at Westmead. PAEDS Network members past and present include Connell J, Dale R, Deverell $M$, Dougherty S, Finucane C, Gibson M, Gold M, Heath C, Hickie L, Hutchinson T, Jones C, Jones J, Kent J, Knight H, Kynaston A, Lee D, Lewis G, Low S, Macartney K, Maclean N, McDonald F, McLaren N, McRae J, Murphy J, Nissen M, Orr C, Orr K, Phillips N, Pym M, Quinn J, Rhind L, Roberts A, Robins C, Rost L, Royle J, Snelling T, Talbott C, Tan S, Trinh L, Vidler L, Walker M, West R, Wharton C, Wood N, and Zurynski Y. PAEDS is supported by the Australian Government Department of Health and Departments of Health in participating jurisdictions (Victoria NSW, South Australia, Western Australia and Queensland). E.T. acknowledges funding from the Grant of The Belgian Kids' Fund for Pediatric research. H.M. acknowledges National Health and Medical Research Council (NHMRC) Practitioner Fellowship funding. P.N.B. acknowledges NHMRC Early Career Fellowship funding. C.C.B. acknowledges NHMRC Career Development Fellowship. A.C.S. acknowledges NHMRC Career Development Fellowship and National Heart Foundation Future Fellowship funding.

\section{REFERENCES}

1. Walker MJ, Barnett TC, McArthur JD, et al. Disease manifestations and pathogenic mechanisms of Group A Streptococcus. Clin Microbiol Rev. 2014;27:264-301

2. Nelson GE, Pondo T, Toews KA, et al. Epidemiology of invasive group A Streptococcal infections in the United States, 2005-2012. Clin Infect Dis. 2016;63:478-486

3. Steer AC, Lamagni T, Curtis N, et al. Invasive group a streptococcal disease: epidemiology, pathogenesis and management. Drugs. 2012;72:1213-1227.

4. Lamagni TL, Darenberg J, Luca-Harari B, et al.; Strep-EURO Study Group. Epidemiology of severe Streptococcus pyogenes disease in Europe. J Clin Microbiol. 2008;46:2359-2367.

5. Carapetis JR, Steer AC, Mulholland EK, et al. The global burden of group A streptococcal diseases. Lancet Infect Dis. 2005;5:685-694.

6. Davies HD, Matlow A, Scriver SR, et al. Apparent lower rates of streptococcal toxic shock syndrome and lower mortality in children with invasive group A streptococcal infections compared with adults. Pediatr Infect Dis J. 1994;13:49-56.

7. Zachariadou L, Stathi A, Tassios PT, et al.; Hellenic Strep-Euro Study Group. Differences in the epidemiology between paediatric and adult invasive Streptococcus pyogenes infections. Epidemiol Infect. 2014;142:512519 .

8. Adalat S, Dawson T, Hackett SJ, et al.; In association with the British Paediatric Surveillance Unit. Toxic shock syndrome surveillance in UK children. Arch Dis Child. 2014;99:1078-1082.

9. Chen KY, Cheung M, Burgner DP, et al. Toxic shock syndrome in Australian children. Arch Dis Child. 2016;101:736-740.

10. Javouhey E, Bolze PA, Jamen C, et al. Similarities and differences between Staphylococcal and Streptococcal toxic shock syndromes in children: results from a 30-case cohort. Front Pediatr. 2018;6:360.

11. Vallalta Morales M, Soriano Navarro CJ, Salavert Lletí M, et al. Group A streptococcal bacteremia: outcome and prognostic factors. Rev Esp Quimioter. 2006;19:367-375.

12. O'Loughlin RE, Roberson A, Cieslak PR, et al.; Active Bacterial Core Surveillance Team. The epidemiology of invasive group A streptococcal infection and potential vaccine implications: United States, 2000-2004. Clin Infect Dis. 2007;45:853-862.

13. Baraldés MA, Domingo P, Mauri A, et al. Group A streptococcal meningitis in the antibiotic era. Eur J Clin Microbiol Infect Dis. 1999;18:572-578.

14. Lamagni TL, Neal S, Keshishian C, et al. Severe Streptococcus pyogenes Infections, United Kingdom, 2003-2004. Emerg Infect Dis 2008;14:202-209.

15. de Almeida Torres RS, Fedalto LE, de Almeida Torres RF, et al. Group A streptococcus meningitis in children. Pediatr Infect Dis J. 2013;32:110 114.

16. van Zitteren LM, Arents NL, Halbertsma F. Group-A-streptococcal meningitis in a 7-year-old child - a rare pathogen in a non-immune compromised patient. BMJ Case Rep 2011;2011.
17. Ben-Abraham R, Keller N, Vered R, et al. Invasive group A streptococcal infections in a large tertiary center: epidemiology, characteristics and outcome. Infection. 2002;30:81-85.

18. Hamilton SM, Bayer CR, Stevens DL, et al. Effects of selective and nonselective nonsteroidal anti-inflammatory drugs on antibiotic efficacy of experimental group A streptococcal myonecrosis. J Infect Dis. 2014;209:1429-1435

19. Bryant AE, Bayer CR, Aldape MJ, et al. The roles of injury and nonsteroidal anti-inflammatory drugs in the development and outcomes of severe group A streptococcal soft tissue infections. Curr Opin Infect Dis. 2015;28:231239.

20. Megged O, Yinnon AM, Raveh D, et al. Group A streptococcus bacteraemia: comparison of adults and children in a single medical centre. Clin Microbiol Infect. 2006;12:156-162.

21. Zurynski Y, McIntyre P, Booy R, et al.; PAEDS Investigators Group. Paediatric active enhanced disease surveillance: a new surveillance system for Australia. J Paediatr Child Health. 2013;49:588-594

22. Harris PA, Taylor R, Thielke R, et al. Research electronic data capture (REDCap)-a metadata-driven methodology and workflow process for providing translational research informatics support. J Biomed Inform. 2009;42:377-381

23. WHO | Disabilities. WHO. Available at: http://www.who.int/topics/disabilities/en/. Accessed Nov 26, 2019.

24. Oliver J, Thielemans E, McMinn A, et al.; PAEDS investigators. Invasive group A Streptococcus disease in Australian children: 2016 to 2018 - a descriptive cohort study. BMC Public Health. 2019;19:1750.

25. Wang B, Clarke M, Thomas N, et al. The clinical burden and predictors of sequelae following invasive meningococcal disease in Australian children. Pediatr Infect Dis J. 2014;33:316-318.

26. Cancellara AD, Melonari P, Firpo MV, et al. Multicenter study on invasive Streptococcus pyogenes infections in children in Argentina. Arch Argent Pediatr. 2016;114:199-208.

27. Vyse A, Anonychuk A, Jäkel A, et al. The burden and impact of severe and long-term sequelae of meningococcal disease. Expert Rev Anti Infect Ther. 2013;11:597-604

28. Allen U, Moore D. Invasive group A streptococcal disease: Management and chemoprophylaxis. Paediatr Child Health. 2010;15:295-302.

29. Shah SS, Hall M, Srivastava R, et al. Intravenous immunoglobulin in children with streptococcal toxic shock syndrome. Clin Infect Dis. 2009;49:13691376.

30. Waddington CS, Snelling TL, Carapetis JR. Management of invasive group A streptococcal infections. J Infect. 2014;69(suppl 1):S63-S69.

31. Carapetis JR, Jacoby P, Carville K, et al. Effectiveness of clindamycin and intravenous immunoglobulin, and risk of disease in contacts, in invasive group a streptococcal infections. Clin Infect Dis. 2014;59:358-365.

32. Kaul R, McGeer A, Norrby-Teglund A, et al. Intravenous immunoglobulin therapy for streptococcal toxic shock syndrome-a comparative observational study. The Canadian Streptococcal Study Group. Clin Infect Dis. 1999;28:800-807

33. Darenberg J, Ihendyane N, Sjölin J, et al.; StreptIg Study Group. Intravenous immunoglobulin $\mathrm{G}$ therapy in streptococcal toxic shock syndrome: a European randomized, double-blind, placebo-controlled trial. Clin Infect Dis. 2003;37:333-340.

34. Walsh A, Edwards H, Fraser J. Over-the-counter medication use for childhood fever: a cross-sectional study of Australian parents. J Paediatr Child Health. 2007;43:601-606.

35. Seale AC, Davies MR, Anampiu K, et al. Invasive Group A Streptococcus Infection among Children, Rural Kenya. Emerg Infect Dis. 2016;22:224 232 .

36. Haggar A, Nerlich A, Kumar R, et al. Clinical and microbiologic characteristics of invasive Streptococcus pyogenes infections in north and south India. J Clin Microbiol. 2012;50:1626-1631.

37. Wong NX, Crawford NW, Oliver J, et al. A cluster of pediatric invasive group a Streptococcus Disease in melbourne, Australia, coinciding with a high-burden influenza season. J Pediatr Infect Dis 2019;14:213-218.

38. Okamoto S, Kawabata S, Nakagawa I, et al. Influenza A virus-infected hosts boost an invasive type of Streptococcus pyogenes infection in mice. JVirol. 2003;77:4104-4112.

39. Ghoneim HE, Thomas PG, McCullers JA. Depletion of alveolar macrophages during influenza infection facilitates bacterial superinfections. $J$ Immunol. 2013;191:1250-1259. 
40. Herrera AL, Huber VC, Chaussee MS. The association between invasive Group A Streptococcal diseases and viral respiratory tract infections. Front Microbiol. 2016;7:342.

41. Ching NS, Crawford N, McMinn A, et al. Prospective Surveillance of Pediatric Invasive Group A Streptococcus Infection. J Pediatr Infect Dis Soc 2019;8:46-52.
42. Vaillancourt S, Guttmann A, Li Q, et al. Repeated emergency department visits among children admitted with meningitis or septicemia: a populationbased study. Ann Emerg Med. 2015;65:625-632.e3.

43. Mearkle R, Saavedra-Campos M, Lamagni T, et al. Household transmission of invasive group A Streptococcus infections in England: a populationbased study, 2009, 2011 to 2013. Eurosurveillance 2017;22:30532. 